\title{
Initial inferior vena cava and aorta diameter parameters measured by ultrasonography or computed tomography does not correlate with vital signs, hemorrhage or shock markers in trauma patients
}

\author{
๑ Ömer Faruk Çelik, M.D., ${ }^{1} \oplus$ Haldun Akoğlu, M.D., ${ }^{2} \oplus$ Ali Çelik, M.D., ${ }^{2} \oplus$ Ruslan Asadov, M.D., ${ }^{3}$ \\ (1) Özge Ecmel Onur, M.D., ${ }^{2} \odot$ Arzu Denizbaşı, M.D. ${ }^{2}$
}

\author{
${ }^{1}$ Department of Emergency Medicine, Cizre State Hospital, Şırnak-Turkey \\ 2Department of Emergency Medicine, Marmara University Pendik Education and Research Hospital, İstanbul-Turkey \\ ${ }^{3}$ Department of Radiology, Marmara University Pendik Training and Research Hospital, İstanbul-Turkey
}

\begin{abstract}
BACKGROUND: Ultrasonography (US) is noninvasive, readily available, and cheap. The diameter of inferior vena cava (dIVC) and its respiratory variation were proposed as a good surrogate of the hemodynamic state. However, recent studies have shown conflicting results, and the value of IVC-derived parameters in the estimation of fluid status and hemorrhage remains unclear.
\end{abstract}

METHODS: This was an observational study of trauma patients who presented to emergency department. dIVC and aorta diameter (dAorta) were measured at the initial US and CT in all patients. The correlation of these measurements and all parameters derived from those measurements along with the initial vital signs and laboratory values of hemorrhage (hemoglobin, hematocrit) and shock (lactate, base excess) were assessed. US and CT values were also compared for accuracy using Bland-Altman analysis.

RESULTS: The final study population was 140, with a mean age of 38 years and $79.3 \%$ were male. dIVC and dAorta did not have any clinically significant correlation with any of the vital signs or laboratory values of hemorrhage or shock when measured by US or CT. A good and significant correlation was observed between dIVC and dAorta measured by US and CT.

CONCLUSION: The value of an initial and single measurement of IVC and aorta parameters in the evaluation of trauma patients should be questioned. However, the change in the measured parameters may be of value and should be investigated in further studies.

Keywords: Aorta; aortacaval index; caval index; collapsibility index; diameter; distensibility index; inferior vena cava; shock; trauma.

\section{INTRODUCTION}

Evaluation of the hemodynamic and perfusion status of a trauma patient is extremely important. Blood pressure and mean arterial pressure (MAP) have been used to define shock state since the advent of medical manometers; central venous pressure (CVP) has been used for monitoring treatment in those patients.
Inferior vena cava diameter (dIVC) and its respiratory variability [collapsibility (dIVC-CI) and distensibility (dIVC-DI) indexes] were defined in the early 80 's. ${ }^{[1,2]}$ Then, in the late 80 's, the utility of dIVC to noninvasively estimate mean right atrial (RA) pressure was studied and reported as a promising index. ${ }^{[3,4]}$ In the 90's, first reports supporting the use of dIVC to estimate the dry weight and fluid status of patients were published. ${ }^{[5-9]}$ However, with the millennium, a paradigm

\footnotetext{
Cite this article as: Çelik ÖF, Akoğlu H, Çelik A, Asadov R, Onur ÖE, Denizbaşı A. Initial inferior vena cava and aorta diameter parameters measured by ultrasonography or computed tomography does not correlate with vital signs, hemorrhage or shock markers in trauma patients. Ulus Travma Acil Cerrahi Derg 2018;24:351-358.

Address for correspondence: Haldun Akoğlu, M.D.

Marmara Üniversitesi Tıp Fakültesi, Acil Tıp Anabilim Dalı, Pendik, İstanbul, Turkey

Tel: +90 216 - 6254545 E-mail: drhaldun@gmail.com

Ulus Travma Acil Cerrahi Derg 2018;24(4):35I-358 DOI: 10.5505/tjtes.20I7.72365 Submitted: 14.07.2017 Accepted: 17.10.2017 Online: 19.06.2018

Copyright 2018 Turkish Association of Trauma and Emergency Surgery
} 
shift has begun in the evaluation of fluid status. In place of RA pressures, a new approach called fluid responsiveness has emerged to guide the fluid therapy. ${ }^{[10]}$ Several methods to evaluate fluid responsiveness were tested including the above mentioned sonographic IVC-related indexes. ${ }^{[10-15]}$ Furthermore, the utility of sonographic IVC indexes to estimate the degree of anemia or blood loss or the hemodynamic response to hemorrhage was also tested. Lyon et al. ${ }^{[1]}$ in their study of healthy blood donors, reported dIVC as a reliable indicator of blood loss. Yanagawa et al. ${ }^{[16]}$ confirmed those findings and found dIVC to correlate with hypovolemia and hemoglobin level of trauma patients with class 3 and 4 shock states. Carr et al. ${ }^{[13]}$ reported that the value of dIVC was correlated with CVP measurements in the intensive care unit (ICU). Other sonographic indexes such as cava-aortic diameter index (dIVC/dAorta) were also tested to find a better IVC-derived parameter. ${ }^{[15]}$ However, recently, negative studies conflicting with these previous reports were published. Resnick et al. ${ }^{[17]}$ denied to observe a significant change in IVC indexes in their study of blood donors for class I shock. Juhl-Olsen et al. ${ }^{[18]}$ also denied to observe a significant correlation between the hemodynamic response to hemorrhage and dIVC or dIVC-Cl in a similar cohort. Similarly, Sobczyk et al. ${ }^{[19]}$ reported that dynamic IVC-derived parameters and CVP were not reliable predictors of fluid responsiveness in the first $6 \mathrm{~h}$ after cardiac surgery. However, the value of IVC-derived parameters in the estimation of fluid status and its correlation with hemorrhage markers or vital signs in trauma patients is still not clear, since different and incomparable cohorts were used in previous research.

Therefore, the aim of this study is to evaluate the utility and correlation of IVC-derived parameters measured by US and CT with vital signs and biomarkers of hemorrhage and shock in trauma patients.

\section{MATERIALS AND METHODS}

\section{Design and Setting}

This is a prospective, observational clinical study with convenience sampling conducted at the emergency department (ED) of a level I trauma center with an annual volume of 200.000 patients between August 20I4 and December 2015.

\section{Selection of Participants}

The study sample consisted of adult patients ( $\geq 18$ years) who presented to ED with multiple traumas, underwent contrast-enhanced thoracoabdominal CT, and met the inclusion criteria. The attending emergency medicine physicians (EPs) decided the eligibility of the patients based on history and physical examination and managed them according to the latest ATLS guidelines. Multiple trauma was defined according to ATLS as more than one anatomical area being affected. Unstable [systolic blood pressure (SBP) $<100 \mathrm{mmHg}$ and/or heart rate $(H R)>100$ beats/min and/or $\geq 4 U$ of packed red blood cells transfused in the trauma bay] vital signs, lack of informed consent, difficulty in sonographic examination, or anatomical defect(s) at the site of sonographic imaging, pregnancy, inability to perform CT (unable to leave the trauma bay for $\mathrm{CT}$, died in ED, referred to the operating room before $\mathrm{CT}$ ), intubation, and known allergies to contrast materials were the exclusion criteria.

\section{Data Collection and Study Procedure}

All multiple trauma patients were evaluated and managed in the trauma bay of ED by EPs. Vital signs [HR, SBP, diastolic blood pressure (DBP), respiratory rate (RR), peripheral oxygen saturation $\left(\mathrm{SpO}_{2}\right)$ ] were electronically measured and recorded. Complete blood count, blood type and match, blood gases, biochemistry, and electrolytes were ordered according to the departmental trauma protocols. Demographics (age, sex), history (trauma type and mechanism, past medical history), results of the laboratory examinations, and official radiology reports were retrospectively collected from the hospital information system.

\section{Measurements \\ US Measurements}

All bedside US examinations were performed by two certified EPs (OFC, AC). Before the patient recruitment period, a two-hour theoretical video-assisted lecture and hands-on training on ICU patients were performed. A certified US performer instructed the lecture on techniques to adequately visualize IVC and aorta, to detect the timing of measurements according to respiratory cycle, anatomical landmarks, and to explain measurements to be conducted. EPs performing the US measurements had at least 3 years of experience in protocols such as e-FAST, RUSH, or POCUS with an average of 500 bedside US examinations per year. In all patients with a decision to obtain thoracoabdominal CT by the attending EP, IVC and aorta-derived US parameters were measured during the e-FAST examination before the patient left ED for CT.

All measurements were recorded in a data collection form by EP performing US. Diameters were measured in maximal inspiration and expiration while the patients were supine with 3.5 Mhz abdominal probes of the two ultrasound machines (Mindray M5, Mindray, P.R.C., and Aloka Prosound 6, Aloka AG, Swiss). Maximum (during expiration, dIVCe) and minimum (during inspiration, dIVCi) IVC diameters were measured $2 \mathrm{~cm}$ proximal to the trifurcation of the hepatic vein, and maximum aortic diameter (dAorta) was measured at the ostium of the renal arteries using real-time B-mode images between the internal anteroposterior walls. Three separate measurements were made and the average was used for the final analysis for each diameter. The IVC collapsibility index (dIVC-Cl) indicates the relative decrease in diameter during the respiratory cycle and is calculated as follows: (dIVCedIVCi)/dIVCe. The IVC distensibility index (IVC-DI) indicates the increase in diameter during inspiration and is calculated 
as follows: (dIVCe-dIVCi)/dIVCi. Those indexes were retrospectively calculated from the dataset.

\section{CT Measurements}

All CT measurements were performed by an academic radiology specialist who was blinded to the results of US examinations on Picture Archiving and Communication System on contrast-enhanced images taken according to the trauma protocol. The specialist had a 5-year experience in abdominal CT reporting and read approximately $30 \mathrm{CT}$ examinations per day. A dedicated MDCT was used for all ED imaging (Siemens ${ }^{\circledR}$ Somatom ${ }^{\circledR}$ Definition Flash CT Scanner, $2 \times 128$ slice stellar detectors with isotrophic resolution of $0.33 \mathrm{~mm}$ and cross-plane resolution of $0.30 \mathrm{~mm}$, Siemens AG, Erlangen, Germany). IVC diameters (dIVC-CT) were measured 2 $\mathrm{cm}$ proximal to the trifurcation of the hepatic vein on axial images, and the aortic diameter (dAorta-CT) was measured at the proximal plane of the ostium of the renal arteries between the internal anteroposterior walls. Three separate measurements were made and the average was used for the final analysis for each diameter.

\section{Other Measurements and Calculations}

The shock index (SI) was defined as HR/SBP. A patient with SI $>0.9$ was considered to have high risk. ${ }^{[20]}$ dIVCe was defined as flat if $\leq 9 \mathrm{~mm}$ and normal if $>9 \mathrm{~mm}$ according to a previous research. ${ }^{[16]}$ All US and CT measurements and collected patient data were retrospectively reviewed from the electronical records for accuracy by a blinded research assistant.

\section{Outcome Measures}

The primary outcome measures were the correlation coefficients between the US indexes, vital parameters, and hemorrhage markers. The secondary outcome measure was the consistency between US and CT measurements.

\section{Statistical Analysis}

Continuous variables were reported as means and standard deviations with $95 \%$ confidence intervals $(\mathrm{Cl})$ or as medians and interquartile ranges (IQR) according to distribution patterns. Student's $\mathrm{t}$ or sign tests were used to compare the independent groups. Categorical variables were reported as proportions and counts and compared using Fisher's exact test. Correlations were calculated as defined by Pearson, and their effect sizes were named according to Dancey and Reidy. [21] Differences of the measurements performed by US and CT were plotted against the averages of the two techniques as defined by Bland and Altman. ${ }^{[22]}$ The sample size was estimated as 82 for the statistical significance of a correlation coefficient of 0.3 with a type I error of $5 \%$ and power of $80 \%$. We decided to enroll two times of this number to achieve the sufficient number of patients at the end of the study. The achieved power of this study for the correlation coefficient of IVC/aorta ratios measured by US and CT was 100\%. Type
I error was accepted as $5 \%$. This study was approved by the ethics committee and was one of the two trials conducted on the same study population. MedCalc Statistical Software version 17 (MedCalc Software bvba, Ostend, Belgium; https:// www.medcalc.org) was used for all analysis.

\section{RESULTS}

The total number of patients enrolled into this study was 164. Nineteen patients (1 1.6\%) were excluded because of incomplete data and five (3\%) due to other exclusion criteria. The final study population was 140 (85.4\%). The median age of the study population was 38 years, and I I I (79.3\%) were male. Demographic characteristics, vital signs, and radiological measurements are presented in Table I.

We found that dIVC and dAorta and all indexes derived from them did not have any clinically important correlation with neither vital parameters (HR, SBP, DBP, MAP) nor hemorrhage $(\mathrm{Hg}, \mathrm{Hct})$ or shock (Lactate, $\mathrm{BE})$ markers when mea-

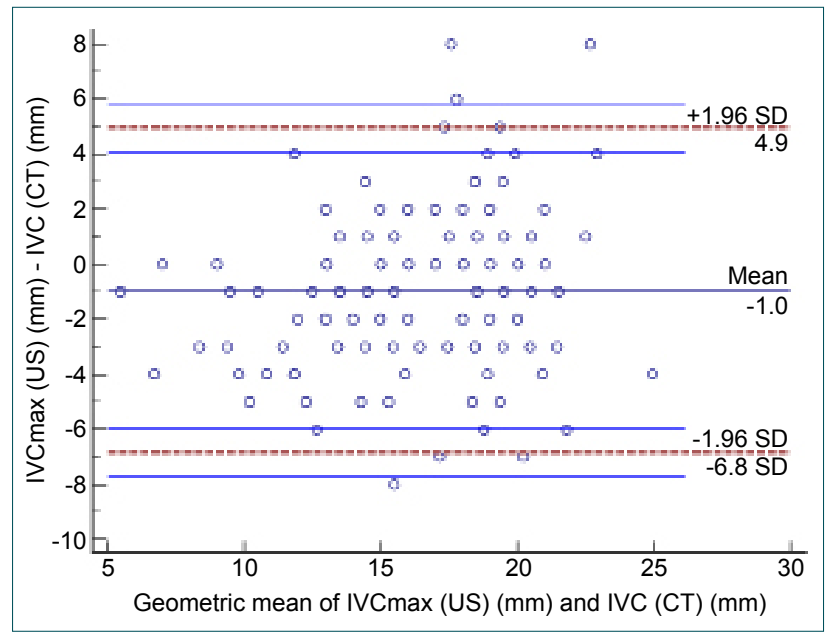

Figure 1. Bland-Altman analysis of dIVC measured by US and CT (US: Ultrasonography; CT: Computed tomography).

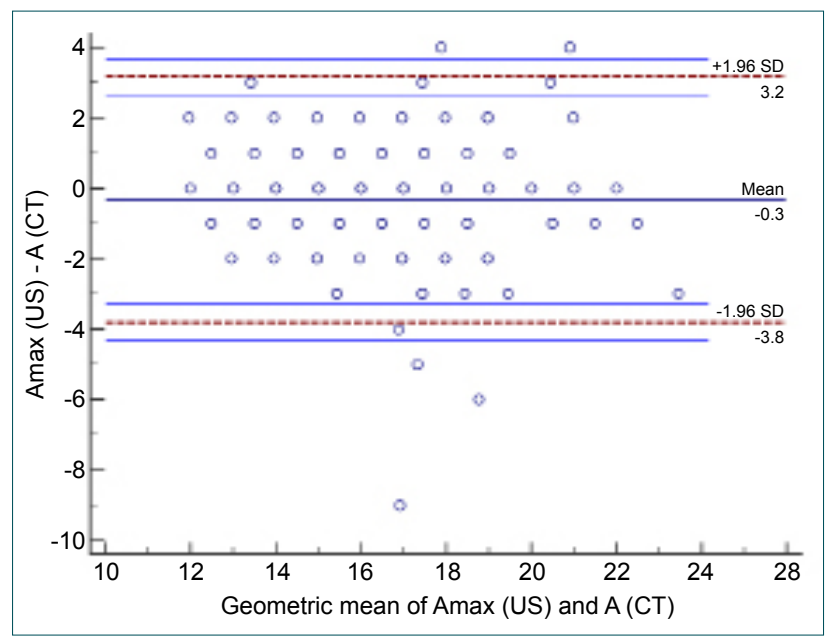

Figure 2. Bland-Altman analysis of dAorta measured by US and CT (US: Ultrasonography; CT: Computed tomography). 
Table I. Demographic and clinical characteristics of the study population according to flat IVC status

\begin{tabular}{|c|c|c|c|c|}
\hline \multirow[b]{2}{*}{ Demographics } & \multirow[b]{2}{*}{ Total } & \multicolumn{2}{|c|}{ IVC } & \multirow[b]{2}{*}{$\mathbf{P}^{*}$} \\
\hline & & Flat IVC & Normal IVC & \\
\hline Age (years), median (IQR) & $38(29,49)$ & 36 & 38 & 0.4524 \\
\hline Male, n (\%) & III (79.3) & $8(72.7)$ & $103(79.8)$ & 0.5774 \\
\hline \multicolumn{5}{|l|}{ Vital Signs, median (IQR) } \\
\hline Systolic blood pressure $(\mathrm{mmHg})$ & $127.5(|| 4.0,|4| .0)$ & 115 & 128 & 0.0054 \\
\hline Diastolic blood pressure $(\mathrm{mmHg})$ & $79.0(70.0,87.5)$ & 75 & 79 & 0.4665 \\
\hline Mean arterial pressure $(\mathrm{mmHg})$ & $93.7(84.8,105.5)$ & 86.7 & 93.7 & 0.0730 \\
\hline Heart rate $(\mathrm{bpm})$ & $89.8(15.7)$ & 93 & 90 & 0.9506 \\
\hline Temperature $(\mathrm{C})$ & $36.6(36.5,36.7)$ & 36.6 & 36.6 & 0.5475 \\
\hline Respiratory rate (/min) & $16(14,18)$ & 16 & 16 & 0.2492 \\
\hline $\mathrm{pSO}_{2}(\%)$ & $98(97,100)$ & 98 & 98 & 0.9091 \\
\hline Shock index & $0.72(0.17)$ & 0.74 & 0.71 & $0.07 / 2$ \\
\hline \multicolumn{5}{|l|}{ Laboratory values } \\
\hline Hemoglobin $(g / d L)$, mean $(S D)$ & $13.8(1.6)$ & 14.3 & 13.9 & 0.6588 \\
\hline Hematocrit $\left(\% / \mathrm{mm}^{3}\right)$, mean $(\mathrm{SD})$ & $41.3(4.4)$ & 42.2 & 41.9 & 0.7188 \\
\hline Lactate $(\mathrm{mmol} / \mathrm{L})$, median $(\mathrm{IQR})(\mathrm{n}=69)$ & $2.3(1.9,3.1)$ & 3.3 & 2.3 & 0.3882 \\
\hline Base Excess (mEq/L), median (IQR) $(n=68)$ & $0.6(-1.3,2.2)$ & 0.4 & 0.6 & 0.9225 \\
\hline \multicolumn{5}{|c|}{ Ultrasonography measurements and indexes, median (IQR) } \\
\hline $\operatorname{dIVCe}(\mathrm{mm})$ & $16.0(13.0,19.0)$ & 8 & 17 & $<0.0001$ \\
\hline $\operatorname{dIVCi}(\mathrm{mm})$ & $8.0(6.5,11.0)$ & 3 & 8 & $<0.0001$ \\
\hline dAorta (mm) & $16.0(15.0,18.0)$ & 15 & 16 & 0.1567 \\
\hline IVC-CI (\%) & $47.4(37.5,56.1)$ & 57.1 & 47.4 & 0.0932 \\
\hline IVC-DI (\%) & $90.0(60.0,127.9)$ & 133.3 & 90.0 & 0.0932 \\
\hline dIVCe/dAorta & $1.00(0.81,1.14)$ & 0.50 & 1.00 & $<0.0001$ \\
\hline \multicolumn{5}{|l|}{ CT measurements and indexes, median (IQR) } \\
\hline dIVC-CT (mm) & $17.0(14.0,20.0)$ & 10.0 & 17.0 & $<0.0001$ \\
\hline dAorta-CT (mm) & $16.0(15.0,18.0)$ & 16.0 & 17.0 & 0.2141 \\
\hline dIVC/dAorta-CT & $1.00(0.87,1.18)$ & 0.64 & 1.05 & $<0.0001$ \\
\hline
\end{tabular}

*Mann-Whitney U test. IVC: Inferior vena cava; IQR: Interquartile ranges; dIVCe: Inferior vena cava diameter during expiration; dIVCi: Inferior vena cava diameter during inspiration; dAorta: Aortic diameter; IVC-Cl: Inferior vena cava-collapsibility index; IVC-DI: Inferior vena cava-distensibility index; $\mathrm{CT}_{\text {: }}$ Computed tomography; $\mathrm{PSO}_{2}$ : peripheral oxygen saturation; SD: Standard deviation.

sured by either US or CT (Table 2). The highest statistically significant correlation coefficient was 0.28 , which was poor.

Both median dIVCe (16 vs. $17 \mathrm{~mm}, \mathrm{p}=0.0890)$ and dAorta ( 16 vs. $16 \mathrm{~mm}, \mathrm{p}=0.1926$ ) were similar between US and CT measurements. Bland-Altman analysis of the measurements is shown in Figures $I$ and 2. Correlational analysis was in accordance with the findings; a good and significant correlation was observed between dAorta $(r=0.73)$ and $\operatorname{dIVC}(r=0.7 \mathrm{I})$ measured by US and CT (Table 3).

When we compared the patients with a flat IVC on US examination with patients with normal IVC, we found SBP to be significantly lower (Table I). However, no significant differences were found for other markers and vital signs.
When we compared the patients according to SI, we found high risk patients to have significantly lower dIVCe and dIVCCT (Table 4). In fact, all US- and CT-derived measurements were lower in high-risk SI group; however, statistical significance was not reached for most of them (Table 4).

\section{DISCUSSION}

In this study, we found that the correlation of dIVC, dAorta, IVC-CI, IVC-DI, and dIVC/dAorta index with any of the vital signs or laboratory values of hemorrhage and shock $(\mathrm{Hg}, \mathrm{Hct}$, Lactate, BE) were poor. In a recent study, Juhl-Olsen et al. ${ }^{[18]}$ measured dIVCe, dIVCi, and IVC-CI before and after $480 \mathrm{~mL}$ of blood donation in $\mathbf{3 7}$ healthy volunteers, and they found no 
Table 2. Correlational analysis of US- and CT-derived measurements with initial vital signs and laboratory values

\begin{tabular}{|c|c|c|c|c|c|c|c|c|}
\hline & Hemoglobin & Hematocrite & SBP & DBP & MAP & Heart rate & Lactate & BE \\
\hline \multicolumn{9}{|c|}{ Ultrasonography } \\
\hline dIVCe & 0.061 & 0.089 & 0.303 & 0.114 & 0.210 & -0.071 & 0.057 & -0.107 \\
\hline $\operatorname{dIVCi}$ & -0.036 & 0.008 & 0.278 & 0.112 & 0.204 & -0.011 & 0.059 & -0.096 \\
\hline dAorta & 0.073 & 0.078 & 0.107 & 0.080 & 0.103 & -0.106 & -0.089 & 0.050 \\
\hline $\mathrm{dIVC} / \mathrm{dA}$ & -0.018 & 0.006 & 0.261 & 0.073 & 0.169 & -0.043 & 0.030 & -0.046 \\
\hline dIVC-Cl & 0.134 & 0.091 & -0.123 & -0.047 & -0.087 & 0.006 & -0.015 & 0.035 \\
\hline dIVC-DI & 0.134 & 0.091 & -0.123 & -0.047 & -0.087 & 0.006 & -0.015 & 0.035 \\
\hline \multicolumn{9}{|c|}{ Computed tomography } \\
\hline $\operatorname{dIVC}$ & 0.115 & 0.144 & 0.280 & 0.160 & 0.226 & -0.035 & 0.152 & -0.028 \\
\hline dAorta & 0.178 & 0.183 & 0.184 & 0.238 & 0.256 & -0.099 & -0.038 & -0.025 \\
\hline $\mathrm{dIVC} / \mathrm{dA}$ & -0.014 & 0.011 & 0.121 & 0.008 & 0.048 & 0 & 0.139 & -0.021 \\
\hline
\end{tabular}

Spearman's rank correlation test was performed. Bold values indicate statistically significant correlations, $p<0.05$. SBP: Systolic blood pressure; DBP: Diastolic blood pressure; MAP: Mean arterial pressure; BE: Base excess; dIVC: Inferior vena cava diameter; dIVCe: Inferior vena cava diameter during expiration; dIVCi: Inferior vena cava diameter during inspiration; dAorta: Aortic diameter; Cl: Collapsibility; DI: Distensibility.

Table 3. Correlational analysis of US- and CT-derived measurements

\begin{tabular}{llrr}
\hline & & Correlation coefficient & p \\
\hline dIVCe-Ultrasonography & dIVC-Computed tomography & 0.714 & $<0.000 I$ \\
dIVCe-Ultrasonography & dAorta-Ultrasonography & 0.355 & $<0.000 I$ \\
dIVCe-Ultrasonography & dAorta-Computed tomography & 0.359 & $<0.000 I$ \\
dIVC-Computed tomography & dAorta-Computed tomography & 0.271 & 0.0012 \\
dAorta-Ultrasonography & dAorta-Computed tomography & 0.732 & $<0.000 I$ \\
dIVCe/dAorta (Ultrasonography) & dIVC/dAorta (Computed tomography) & 0.583 & $<0.000$ I \\
\hline
\end{tabular}

Spearman's rank correlation test was performed. dIVCe: Inferior vena cava diameter during expiration; dIVC: Inferior vena cava diameter; dAorta: Aortic diameter; US: Ultrasonography; CT: Computed tomography.

correlation between dIVCe, dIVCi, IVC-Cl and cardiac output (CO) measurements. They claimed that IVC-Cl and dIVCe did not correlate with the hemodynamic response generated by early hemorrhage. Sabaghian et al. ${ }^{[23]}$ studied the correlation between US dIVC, IVC-Cl, and IVC-DI measurements and total (TBW) and extracellular (ECW) water content measured by bio-impedence analysis in patients with chronic HD before and after HD. They found the highest correlation coefficient to be $\mathbf{0 . 2 7}$, which was also poor and almost similar to our findings. In another study, IVC-CI, IVC-DI, and dIVCI dAorta index failed to reliably predict fluid responsiveness

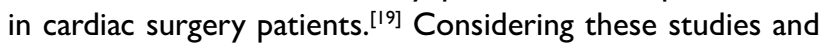
our findings, one may think rather than a single and baseline measurement of an dIVC or any parameter derived from it, the change in serial measurements may be a better estimate. Indeed, Lyon et al. ${ }^{\left[{ }^{\prime \prime}\right]}$ observed a 5-mm decrease in dIVC after $450 \mathrm{cc}$ of blood loss in a similar healthy blood donor cohort of 3 I volunteers and claimed dIVC as a reliable indicator of blood loss. On the contrary, in a study performed on healthy blood donors, Resnick et al. ${ }^{[17]}$ failed to demonstrate a clin- ically significant change in dIVCe, dIVCi, and IVC-Cl after blood donation. Dipti et al. ${ }^{[24]}$ performed a meta-analysis of studies comparing dIVCe between shock vs. non-shock states and reported a mean difference of $6.26 \mathrm{~mm}$, which was significant. The value of defining a single standard range as normal for everyone was questioned as well. In a study of adult hemodialysis patients, Cheriex et al. ${ }^{[5]}$ proposed the optimal values of IVC diameter relative to BSA (8 to $11.5 \mathrm{~mm} / \mathrm{m}^{2}$ ), which is hard to accurately and practically obtain. To overcome this problem, Kosiak et al. ${ }^{[15]}$ introduced dIVC/dAorta index as a promising relative measurement parameter. Several other studies showed a significant relationship between dIVC/dAorta index and CVP; unfortunately, the value of CVP as a good surrogate marker of fluid status was recently questioned. ${ }^{[25,26]}$ In more recent studies, dIVC/dAorta index was shown to have a low predictive value and more susceptible to patient characteristics than IVC. ${ }^{[19,27-29]}$ In this study, we classified patients according to their SI at admission as low and high risk, and we found the differences in dIVCe and dIVC$\mathrm{CT}$ to be statistically significant, and dAorta-US and CT at 
Table 4. Demographic and clinical characteristics of the study population according to shock index

\begin{tabular}{|c|c|c|c|}
\hline \multirow[b]{2}{*}{ Demographics } & \multicolumn{2}{|c|}{ Shock index } & \multirow[b]{2}{*}{$\mathbf{p}^{*}$} \\
\hline & $\begin{array}{l}\text { Shock index } \leq 0.9 \\
(n=123)\end{array}$ & $\begin{array}{c}\text { Shock index }>0.9 \\
(n=17)\end{array}$ & \\
\hline Age (years), median (IQR) & 38 & 38 & 0.6368 \\
\hline \multicolumn{4}{|l|}{ Male, n (\%) } \\
\hline \multicolumn{4}{|l|}{ Vital signs, median (IQR) } \\
\hline Systolic blood pressure (mmHg) & 129 & 104 & $<0.0001$ \\
\hline Diastolic blood pressure $(\mathrm{mmHg})$ & 80 & 70 & $<0.0001$ \\
\hline Mean arterial pressure $(\mathrm{mmHg})$ & 96 & 81 & $<0.0001$ \\
\hline Heart rate $(\mathrm{bpm})$ & 87 & 106 & $<0.0001$ \\
\hline Temperature (C) & 36.7 & 36.6 & 0.2788 \\
\hline Respiratory rate (/min) & 16 & 16 & 0.2344 \\
\hline $\mathrm{pSO}_{2}(\%)$ & 98 & 99 & 0.2443 \\
\hline Shock index & 0.69 & 0.98 & $<0.0001$ \\
\hline \multicolumn{4}{|l|}{ Laboratory values } \\
\hline Hemoglobin (g/dL), mean (SD) & 13.9 & 12.8 & 0.0884 \\
\hline Hematocrit $\left(\% / \mathrm{mm}^{3}\right)$, mean $(\mathrm{SD})$ & 42.0 & 39.2 & 0.0720 \\
\hline Lactate $(\mathrm{mmol} / \mathrm{L})$, median $(\mathrm{IQR})(\mathrm{n}=69)$ & 2.2 & 2.6 & 0.2101 \\
\hline Base excess (mEq/L), median (IQR) $(n=68)$ & 0.65 & -1.00 & 0.3542 \\
\hline \multicolumn{4}{|c|}{ Ultrasonography measurements and indexes, median (IQR) } \\
\hline dIVCe $(m m)$ & 16 & 15 & 0.0386 \\
\hline dIVCi $(\mathrm{mm})$ & 8 & 7 & 0.2607 \\
\hline dAorta (mm) & 16 & 15 & 0.0568 \\
\hline IVC-Cl (\%) & 47.4 & 45.0 & 0.8782 \\
\hline IVC-DI (\%) & 90.0 & 81.8 & 0.8782 \\
\hline dIVCe/dAorta & 1.00 & 0.89 & 0.0964 \\
\hline \multicolumn{4}{|l|}{ CT measurements and Indexes, median (IQR) } \\
\hline dIVC-CT (mm) & 17 & 15 & 0.0080 \\
\hline dAorta-CT (mm) & 17 & 16 & 0.0611 \\
\hline dIVC/dAorta-CT & 1.00 & 0.89 & 0.1280 \\
\hline
\end{tabular}

*Mann-Whitney U test. IVC: Inferior vena cava; IQR: Interquartile ranges; dIVCe: Inferior vena cava diameter during expiration; dIVCi: Inferior vena cava diameter during inspiration; dAorta: Aortic diameter; IVC-Cl: Inferior vena cava-collapsibility index; IVC-DI: Inferior vena cava-distensibility index; CT: Computed tomography; $\mathrm{PSO}_{2}$ : Peripheral oxygen saturation; SD: Standard deviation.

significance margin. However, the correlation between these parameters and biomarkers of hemorrhage and shock was low. It seems from the literature and our findings that there is a slight relationship between dIVC, dAorta, and shock state. However, we still do not have clearly defined reference values of dIVC, dAorta, or relative parameters for pediatric and adult patients, and the predictive value of a single measurement at admission is low. Despite the significant difference, the difference in dIVCe was just I $\mathrm{mm}$ when patients were grouped according to SI; therefore, this difference cannot be regarded as clinically important.

We found that diameters measured by US and CT were highly correlated. Knaut el al. ${ }^{[30]}$ compared dAorta by US and CT in a double-blinded, prospective study of 104 patients and concluded that the measurements were highly correlated, similar to our findings. Therefore, the change in relative parameters such as dIVC/dAorta index theoretically may have more value in predicting hemorrhage or shock state. However, we were unable to show a significant difference in patients according to SI. Further studies are needed to investigate the value of this parameter relative to a more objective standard, such as stroke volume or $\mathrm{CO}$.

\section{Limitations}

As in all studies involving human measurements, there was a slight chance of measurement error. However, to minimize 
this, all measurements were performed thrice and the mean of those measurements was used for the final analysis. In this study, unstable patients were excluded. This may have hampered to identify significant differences in diameters according to shock state.

\section{Conclusion}

dIVC and dAorta measured at the time of ED admission by US or CT and the parameters derived from them were not correlated with blood pressure, heart rate, hemoglobin, and hematocrit, lactate or base excess levels in nonintubated, undifferentiated, adult trauma patients. Therefore, the value of an initial and single measurement of those parameters in the evaluation of trauma patients should be questioned. However, the change in the relative parameters may still be of value and should be investigated in further studies.

\section{Conflict of interest: None declared.}

\section{REFERENCES}

1. Mintz GS, Kotler MN, Parry WR, Iskandrian AS, Kane SA. Real-time inferior vena caval ultrasonography: normal and abnormal findings and its use in assessing right-heart function. Circulation 1981;64:1018-25.

2. Moreno FL, Hagan AD, Holmen JR, Pryor TA, Strickland RD, Castle $\mathrm{CH}$. Evaluation of size and dynamics of the inferior vena cava as an index of right-sided cardiac function. Am J Cardiol 1984;53:579-85.

3. Simonson JS, Schiller NB. Sonospirometry: a new method for noninvasive estimation of mean right atrial pressure based on two-dimensional echographic measurements of the inferior vena cava during measured inspiration. J Am Coll Cardiol 1988;11:557-64. [CrossRef]

4. Kircher BJ, Himelman RB, Schiller NB. Noninvasive estimation of right atrial pressure from the inspiratory collapse of the inferior vena cava. Am J Cardiol 1990;66:493-6. [CrossRef]

5. Cheriex EC, Leunissen KM, Janssen JH, Mooy JM, van Hooff JP. Echography of the inferior vena cava is a simple and reliable tool for estimation of 'dry weight' in haemodialysis patients. Nephrol Dial Transplant 1989;4:563-8.

6. Mandelbaum A, Ritz E. Vena cava diameter measurement for estimation of dry weight in haemodialysis patients. Nephrol Dial Transplant 1996;11 Suppl 2:24-7. [CrossRef]

7. Leunissen KM, Kouw P, Kooman JP, Cheriex EC, deVries PM, Donker $\mathrm{AJ}$, et al. New techniques to determine fluid status in hemodialyzed patients. Kidney Int Suppl 1993;41:S50-6.

8. Kusaba T, Yamaguchi K, Oda H. Echography of the inferior vena cava for estimating fluid removal from patients undergoing hemodialysis. Nihon Jinzo Gakkai Shi 1996;38:119-23.

9. Krause I, Birk E, Davidovits M, Cleper R, Blieden L, Pinhas L, Gamzo $Z$, et al. Inferior vena cava diameter: a useful method for estimation of fluid status in children on haemodialysis. Nephrol Dial Transplant 2001;16:1203-6. [CrossRef]

10. Feissel M, Michard F, Faller JP, Teboul JL. The respiratory variation in inferior vena cava diameter as a guide to fluid therapy. Intensive Care Med 2004;30:1834-7. [CrossRef]

11. Lyon M, Blaivas M, Brannam L. Sonographic measurement of the inferior vena cava as a marker of blood loss. Am J Emerg Med 2005;23:4550. [CrossRef]
12. Jardin F, Vieillard-Baron A. Ultrasonographic examination of the venae cavae. Intensive Care Med 2006;32:203-6. [CrossRef]

13. Carr BG, Dean AJ, Everett WW, Ku BS, Mark DG, Okusanya O, et al. Intensivist bedside ultrasound (INBU) for volume assessment in the intensive care unit: a pilot study. J Trauma 2007;63:495-500. [CrossRef]

14. Chen L, Kim Y, Santucci KA. Use of ultrasound measurement of the inferior vena cava diameter as an objective tool in the assessment of children with clinical dehydration. Acad Emerg Med 2007;14:841-5. [CrossRef]

15. Kosiak W, Swieton D, Piskunowicz M. Sonographic inferior vena cava/ aorta diameter index, a new approach to the body fluid status assessment in children and young adults in emergency ultrasound-preliminary study. Am J Emerg Med 2008;26:320-5. [CrossRef]

16. Yanagawa Y, Nishi K, Sakamoto T, Okada Y. Early diagnosis of hypovolemic shock by sonographic measurement of inferior vena cava in trauma patients. J Trauma 2005;58:825-9. [CrossRef]

17. Resnick J, Cydulka R, Platz E, Jones R. Ultrasound does not detect early blood loss in healthy volunteers donating blood. J Emerg Med 2011;41:270-5. [CrossRef]

18. Juhl-Olsen P, Vistisen ST, Christiansen LK, Rasmussen LA, Frederiksen CA, Sloth E. Ultrasound of the inferior vena cava does not predict hemodynamic response to early hemorrhage. J Emerg Med 2013;45:592-7.

19. Sobczyk D, Nycz K, Andruszkiewicz P. Bedside ultrasonographic measurement of the inferior vena cava fails to predict fluid responsiveness in the first 6 hours after cardiac surgery: a prospective case series observational study. J Cardiothorac Vasc Anesth 2015;29:663-9. [CrossRef]

20. Cannon CM, Braxton CC, Kling-Smith M, Mahnken JD, Carlton E, Moncure M. Utility of the shock index in predicting mortality in traumatically injured patients. J Trauma 2009;67:1426-30. [CrossRef]

21. Dancey CP, Reidy J. Statistics Without Maths for Psychology. 4th ed. Harlow: Pearson Education Ltd., 2007.

22. Bland JM, Altman DG. Statistical methods for assessing agreement between two methods of clinical measurement. Lancet 1986;1:307-10.

23. Sabaghian T, Hajibaratali B, Samavat S. Which echocardiographic parameter is a better marker of volume status in hemodialysis patients? Ren Fail 2016;38:1659-64. [CrossRef]

24. Dipti A, Soucy Z, Surana A, Chandra S. Role of inferior vena cava diameter in assessment of volume status: a meta-analysis. Am J Emerg Med 2012;30:1414-9.e1. [CrossRef]

25. El-Baradey GF, El-Shmaa NS. Does caval aorta index correlate with central venous pressure in intravascular volume assessment in patients undergoing endoscopic transuretheral resection of prostate? Saudi J Anaesth 2016;10:174-8. [CrossRef]

26. Ciozda W, Kedan I, Kehl DW, Zimmer R, Khandwalla R, Kimchi A. The efficacy of sonographic measurement of inferior vena cava diameter as an estimate of central venous pressure. Cardiovasc Ultrasound 2016;14:33.

27. Modi P, Glavis-Bloom J, Nasrin S, Guy A, Chowa EP, Dvor N, et al. Accuracy of Inferior Vena Cava Ultrasound for Predicting Dehydration in Children with Acute Diarrhea in Resource-Limited Settings. PLoS One 2016;11:e0146859. [CrossRef]

28. Gui J, Guo J, Nong F, Jiang D, Xu A, Yang F, et al. Impact of individual characteristics on sonographic IVC diameter and the IVC diameter/ aorta diameter index. Am J Emerg Med 2015;33:1602-5. [CrossRef]

29. Ng L, Khine H, Taragin BH, Avner JR, Ushay M, Nunez D. Does bedside sonographic measurement of the inferior vena cava diameter correlate with central venous pressure in the assessment of intravascular volume in children? Pediatr Emerg Care 2013;29:337-41. [CrossRef]

30. Knaut AL, Kendall JL, Patten R, Ray C. Ultrasonographic measurement of aortic diameter by emergency physicians approximates results obtained by computed tomography. J Emerg Med 2005;28:119-26. [CrossRef] 
ORİJINAL ÇALIŞMA - ÖZET

Ultrason ve bilgisayarlı tomografi ile travma hastalarının başvurusu esnasında ölçülen inferiyor vena kava ve aort çap parametreleri yaşamsal bulgular, kanama ve şok belirteçleri ile korele değildir

Dr. Ömer Faruk Çelik, ${ }^{1}$ Dr. Haldun Akoğlu, ${ }^{2}$ Dr. Ali Çelik, ${ }^{2}$ Dr. Ruslan Asadov, ${ }^{3}$ Dr. Özge Ecmel Onur, ${ }^{2}$ Dr. Arzu Denizbaşı ${ }^{2}$

${ }^{1}$ Cizre Devlet Hastanesi, Acil Tıp Kliniği, Şırnak

${ }^{2}$ Marmara Üniversitesi Pendik Eğitim ve Araştırma Hastanesi, Acil Tıp Anabilim Dalı, İstanbul

${ }^{3}$ Marmara Üniversitesi Pendik Eğitim ve Araştırma Hastanesi, Radyoloji Anabilim Dalı, İstanbul

AMAÇ: Ultrason (US) invaziv olmayan, kolaylıkla erişilebilir ve ucuz bir yöntemdir. İnferiyor vena kava (IVC) çapı ve solunumsal değişkenliği hemodinamik durumun iyi bir göstergesi olarak bildirilmiştir. Ancak, IVC temelli parametrelerin sıvı ve kanama durumunu belirleme gücü yönünden son çalışmalar birbiriyle tutarsızdır.

GEREÇ VE YÖNTEM: Bu acil servise başvuran hastalarda gerçekleştirilen gözlemsel bir çalışmadır. IVC ve aorta çapları hastaların ilk başvurusunda US ve bilgisayarlı tomografi (BT) ile ölçülmüştür. Bu ölçümlerin ve bu ölçümlerden köken alan parametrelerin ilk yaşamsal bulgular ile kanama ve şokun laboratuvar belirteçleriyle korelasyonu değerlendirilmiştir. Ayrıca US ve BT ölçümlerinin tutarlılı̆̆ Bland-Altman analiziyle incelenmiştir. BULGULAR: Çalışmanın son örneklemi I 40 hasta olup, ortalama yaş 38 yıl, erkek oranı \%79.3'dür. Inferiyor vena kava ve aorta çapları yaşamsal bulgular ile kanama ve şok belirteçleri ile, US ya da BT ile ölçülmesinden bağımsız şekilde klinik olarak anlamlı bir korelasyonu tespit edilmemiştir. Ultrason ve BT ile ölçülen IVC çaplarının birbiri ike tutarlılı̆ı ve korelasyonu yüksektir.

TARTIŞMA: Travma hastalarıın değerlendirmesinde tek sefer ve ilk başvuruda ölçülen IVC ve aort parametrelerinin değeri sorgulanmalıdır. Ancak, takip esnasında bu parametrelerdeki değişimin değeri yapılacak ilerki çalışmalarda yeniden değerlendirilmelidir.

Anahtar sözcükler: Aort; inferiyor vena kava; şok; travma.

Ulus Travma Acil Cerrahi Derg 2018;24(4):35I-358 doi: 10.5505/tjtes.2017.72365 